\title{
Skin Findings Related to COVID-19, the Review of the Current Literature
}

\author{
Sezin Ünlü Açıkel ${ }^{1}$ (D) Akın Aktaş ${ }^{2}$ (D) \\ 1 Konya City Hospital, Department of Dermatology and Venereology, Konya, Turkey \\ 2 Ankara Yıldırım Beyazıt University Medical Faculty, Department of Dermatology and Venereology, Ankara, Turkey
}

\begin{abstract}
COVID-19 is an acute respiratory infection that is caused by SARS-CoV2 and it was declared a pandemic by the World Health Organization in March 2020. Many different skin manifestations such as urticarial lesions, maculovesicular lesions, papulovesicular lesions, MIS-C lesions, purpuric / petechial lesions, livedoid lesions, and thrombotic-ischemic lesions have been described in this infection. Thus, timely and accurate identification of skin findings might be beneficial in terms of early diagnosis. In addition, the type of lesion gives information about prognosis in some cases. The exact mechanism for the formation of skin lesions is not known, but the immune system activation, the direct cytopathic effect of the virus, the microvascular damage, hypercoagulopathy and complement activation are factors that are thought to play a role in the pathogenesis. Further studies are required in order to systematize the skin findings seen in COVID-19 and to reveal their mechanisms. Furthermore, the COVID-19 pandemic has also induced various skin complications such as pressure sores, dry skin, dermatitis, and contact urticaria due to the use of personal protective equipment (PPE). Besides, the use of PPE might cause exacerbation of skin diseases such as acne, rosacea, seborrheic dermatitis, atopic dermatitis.
\end{abstract}

Key words: COVID-19, Skin Symptoms, SARS-CoV2, Pandemic.

\section{INTRODUCTION}

The COVID-19 pandemic, caused by SARS-CoV-2 in humans, is going on spreading rapidly and leading to a global health crisis (1). The effects of COVID-19 on the skin can be examined under four headings: skin findings due to lifestyle changes, cutaneous adverse events due to drugs used in the treatment of COVID-19, skin lesions due to COVID-19 and effects of COVID-19 and its treatment on primary skin diseases.
Although new data are being obtained every day, there is still much unknown about the clinical features of the disease, including cutaneous manifestations. SARS-CoV-2, a new strain of the coronavirus family, has been associated with many viral exanthems. Certain adenovirus serotypes, just like SARS-CoV-2, can also be caused by vesicular, maculopapular, or petechial exanthems (2). 
A wide range of mucocutaneous findings can be seen in viral diseases. In patients with skin rash and fever, identifying the skin lesions accurately and on time makes a great contribution to the diagnosis. Skin findings seen in COVID-19 can be handled in two main categories as inflammatory exanthems and vascular lesions. Inflammatory exanthems are maculopapular, urticarial, vesicular (chickenpox-like) lesions and MIS-C eruptions. Vascular lesions associated with COVID-19 can be classified as chilblain-like lesions, petechiae / purpuric eruption, and livedoid lesions (3). Some of these lesions, for instance; maculopapular eruptions and urticarial, can also be seen in the course of many other viral diseases, although some appear specific to COVID-19, such as varicella-like lesions (4). Some lesions may precede other symptoms and a careful evaluation of skin findings might be beneficial in terms of early diagnosis and measures to be taken $(5,6)$. Moreover, it is stated that many lesions might show the way to future complications and disease prognosis (7).

At the beginning of the pandemic, the frequency of skin findings in COVID-19 disease was stated as $0.2 \%$ in reports from China (8) However, it is seen that this rate increased up to $20 \%$ in later Italian reports (9). In a prospective study conducted in France, the frequency of skin findings in the course of COVID-19 disease was reported as $4.9 \%(10)$.

\section{COMMON SKIN MANIFESTATIONS OF COVID-19}

\section{Urticarial Lesions}

Urticaria; It is a dermatosis with swelling or angioedema or both. Mast cell degranulation plays a role in its physiopathology. There are many triggers in its etiology (11). Viral infections are common causes of urticarial lesions. Different rates of urticarial lesions have been reported in case series published on the skin findings of COVID-19. When the cases in the literature are examined, it has been stated that in the course of COVID-19, urticarial lesions can be seen more frequently in women and also in a wide age range. Casas Galvan et al. reported that they detected urticarial lesions in 73 patients out of $375(19 \%)$ and the lesions were mostly located on the trunk. They found urticarial lesions limited to the palmar region in only a few patients. Urticarial lesions started before the symptoms of COVID-19 in three of these patients, concurrently in 43 of them, and after the symptoms in 25 patients. In addition, the mean lesion duration was found as 6.8 days (12). In the case series of Recalcati et al., 18 patients out of $88(20.4 \%)$ diagnosed with COVID-19 had diseaserelated skin lesions, while only three of these 18 patients had urticarial lesions and there was no significant relationship between disease severity and presence of urticarial lesions (9). Henry et al. reported a case with limited urticarial lesions to the face and extremities without fever in a female patient with a positive PCR test (13). In contrast, van Damme et al. reported two COVID-19 patients whose initial symptoms were fever and widespread urticarial rash (14). When the cases in the literature are examined, it is seen that the cases are treated with classical treatment protocols (corticosteroid, antihistamine) in acute urticaria.

Although urticarial lesions can be seen in the course of COVID-19 disease, many agents used in the treatment of the disease can also be a trigger of urticaria. In addition, urticarial lesions can be the signs of hyperactivation of the immune system seen in the course of COVID-19, except for drug side effects (15).

During the COVID-19 pandemic, all patients with urticarial rash should be reviewed for the viral pandemic infection, regardless of whether they have additional symptoms or not, in terms of being an early marker of the disease. In this way, a possible infection can be diagnosed at an early stage. With an early diagnosis, it is possible to protect the patient from the complications that might occur later and also to prevent possible transmission by providing the patient's isolation in the early period.

\section{Maculopapular Lesions}

Maculopapular rash is a common skin manifestation that can be caused by many different reasons such as drug side effects, viral infections, and bacterial infections. When it is found with viral and bacterial infections, it usually accompanies symptoms such as headache, muscle pain, fever, and respiratory distress. Hepatitis B, hepatitis C, HIV, infectious mononucleosis, measles, and hand-foot-mouth disease can be mentioned as examples of viral infections that can cause maculopapular rash (16).

It can be said that the most common cutaneous lesion in the course of COVID-19 is maculopapular eruption. In the case series of Casas Galvan et al., $47 \%$ of 375 patients 
with COVID-19 had maculopapular rash. Itching was reported to be seen in the $56 \%$ of the patients with a maculopapular rash. In this study, it was reported that the lesions in some cases were in the form of squamous plaques with perifollicular localization, whereas pityriasis rosea-like lesions were detected in some of the patients. In the same study, it was mentioned that a small number of patients had indurated papules similar to erythema elevatum diutinum or lesions resembling erythema multiforme (12). In the case series published by De Giorgi et al., the incidence of maculopapular eruption in COVID-19 patients was reported as 70\% (17). Recalcati et al. described maculopapular eruption in 14 of 18 patients with COVID-19 infection (9). In the literature, the duration of the lesion is seen in a wide range of days, from 2 to 33, in different reports (18-24). While maculopapular rashes in the course of pandemic infection are mostly seen in middleaged patients, there are also reported cases in young people and children $(12,25)$. In a large series of cases, maculopapular lesions have been reported to begin concurrently with symptoms of COVID-19, while in a series of fewer cases, lesions have been reported to begin later than symptom onset (27.6-27.85 days) $(12,24-27)$. The duration of the lesion varies between 4 and 16 days $(12,25)$.

The histopathology of maculopapular lesions varies according to the duration of the lesion. Moderate epidermal spongiosis, perivascular lymphocytic and eosinophilic infiltrates in the dermis are observed in early lesions, while perivascular lymphocytic infiltration and histiocytes between collagen fibers are found in late lesions (25).

In some studies in the literature, it has been stated that maculopapular rash might be related to the severity of the disease, while the $2 \%$ mortality rate of patients with maculopapular rash supports this view (12).

Patients with maculopapular rash can be given corticosteroid and antihistamine treatment, and it is possible to follow them only with treatment for infectious disease. While Avellano Moreno et al. reported that the lesions regressed in 5 days with intravenous corticosteroids and antihistamines, Moray-olive et al. followed the patients without treatment and reported that the average recovery time was 5 days $(21,22)$.

\section{Papulovesicular Eruption (Varicella-like)}

Vesicle is the term used to describe water-filled bubbles less than $1 \mathrm{~cm}$ in diameter seen on the skin. In addition to drug eruptions and primary cutaneous diseases, it can often be seen during the course of various bacterial and viral infections. Varicella, herpes simplex, and virus infections are viral diseases with vesicular lesions (16).

Infection-related vesicular lesions can be localized or widely scattered. The incidence of vesicular lesions in the course of COVID-19 appears to be between 3.77\% and $15 \%$ in the literature. The reported cases are mostly middle-aged patients and the distribution of the lesions in these patients is mostly limited to the trunk, while a small number of patients have extremity involvement $(12,26,28-31)$.

Fernandez-Nieto et al. observed COVID-19 patients and found that lesions in two different patterns, diffuse and localized patterns, could be seen in 24 patients with vesicular lesions. In 18 of these patients, $7-8 \mathrm{~mm}$ sized papules, vesicles and pustules, which are Common polymorphic lesions, were seen on the trunk, palms and soles. In other patients, a monomorphic, vesicular eruption with a local pattern, which is $3-4 \mathrm{~mm}$ in diameter, mostly involving the trunk, was observed. There is no difference between the two groups in terms of demographic characteristics and severity of COVID-19. In this study, the average age of the patients was 45 and 18 of the patients were female. Lesions developed before the symptoms of COVID-19 in two of the patients, concurrently in three patients, and after the symptoms in 19 patients. The mean latent period was 14 days for these 19 patients, and the mean duration of regression of vesicular lesions is 10 days. Pulmonary involvement was observed in 10 of the COVID-19 patients with vesicular lesions, and only one patient needed an intensive care unit. Mild disease symptoms were observed in the remaining patients (30).

Galvan Casas et al. reported the incidence of vesicular lesions as $9 \%$ in a case series of 375 patients. In this study, while monomorphic vesicles were located on the trunk and extremities were observed in most of the patients, larger, tense, serohemorrhagic lesions were observed in a few patients. The average age of the patients was 45.6 , and it was reported that $56 \%$ of the patients were women. It was observed that the lesions started before the onset of symptoms in 5 patients, after the symptoms in 10 patients, and simultaneously with the symptoms of the disease in 
19 patients. While the disease that was observed in these patients was moderate, it was reported that the mean regression time of the lesions was 10.4 days (12).

Recalcati et al. reported varicella-like lesions in one patient out of 18 patients, and Marzano et al. reported varicellalike lesions in 12 patients out of 22 patients diagnosed with COVID-19 and they stated that varicella-like rash could be a specific skin manifestation of COVID-19 disease $(9,31)$.

In two studies in the literature, it is seen that the histopathological findings of vesicular lesions were examined, and histopathological findings in these studies were found to be compatible with the histopathological findings of viral infection previously described. In the first study, histopathological examination was performed on the lesions of two patients, and moderate acantholysis was reported with intraepidermal vesicles. In the second study, histopathological examination was performed in seven patients and mild epidermal atrophy, basal vacuolar degeneration, basket weave pattern hyperkeratosis, multinuclear hyperchromatic keratinocytes and dyskeratotic cells were reported $(30,31)$.

There are various speculations regarding the mechanisms of vesicular lesions. Criado et al. stated that the immune system activation seen during the course of infection can also affect the skin. Moreover, in the same study, they also hypothesized that the virus could trigger vesicular lesions by direct cytopathic effect on the endothelium of the dermal vessels (15).

In contrast to urticarial and maculopapular lesions, it is thought that the drugs used in the treatment do not have a role in the etiology of vesicular lesions seen in COVID-19 (30). Vesicular lesions are thought to be associated with intermediate severity of COVID-19 (12,30). Symptomatic treatments such as antihistamines and topical antibiotics are used in the treatment of papulovesicular lesions. Vesicular lesions have been defined as the specific skin lesion of COVID-19 and the recognition of these lesions is very important for the diagnosis of the disease.

\section{Multisystem Inflammatory Syndrome in Children (MIS-C) Lesions}

In the early stages of the pandemic, it was thought that serious complications related to COVID-19 were not seen in children. This belief has lost its validity with the reporting of pediatric patients with severe autoimmune and auto inflammatory symptoms similar to Kawasaki disease in the United Kingdom (32). Later, Verdoni et al. reported that the incidence of Kawasaki-like disease increased almost 30-fold and that antibodies against SARS-CoV-2 were found positive in these patients (33). And then this serious disease, named MIS-C, started to be reported from all over the world. Although MIS-C has many common findings overlapping with Kawasaki disease, it can be seen in older children and adolescents compared to Kawasaki disease, and the more frequent cardiac involvement in these cases is the different features of MIS-C from Kawasaki disease (34). Polymorphic eruptions in the form of maculopapular, erythema multiform-like or diffuse erythroderma, which are among the diagnostic criteria for Kawasaki disease, are similarly observed in MIS-C cases (33). In the case series published by Whittaker et al., it was reported that 30 patients out of 58 diagnosed with MIS-C had erythematous lesions and one patient developed additional purpuric lesions (35) Similarly, in a retrospective study by Miller et al., 31 patients out of 44 diagnosed with MIS-C were reported to have skin findings. Skin findings in these patients were the third most common symptoms after fever and gastrointestinal symptoms (36). In most of the reports, it was stated that patients with MIS-C diagnosis had widespread skin involvement, whereas in the study of Hameed et al., 13 patients out of 35 (37\%) with MIS-C had skin findings and these skin lesions could be seen in different patterns, such as extremity, facial or diffuse (37). Although the etiology of Kawasaki disease is largely unknown, it is stated that there is a genetic predisposition on the ground. Similarly, more studies are needed to fully understand the underlying mechanisms in the occurrence of MIS-C disease and its relationship with COVID-19 (38).

\section{Petechial / Purpuric Lesions}

Purpuric rashes associated with infection might occur due to the toxic vascular effects of the infection, vascular invasion of the infectious agent or diffuse intravascular coagulation caused by the direct vascular toxic effects of the infection. Petechial/purpura as a skin manifestation associated with COVID-19 has been reported less frequently than other lesions (12).

In a retrospective study of 277 patients with skin lesions diagnosed with COVID-19 in France, petechial / purpuric rash was reported in only $3 \%$ of the patients. It has been reported that these lesions might be widespread, acrally 
located or limited (26). In another study, it was reported that the lesions were limited to the distal extremities in most patients with petechial rash (29).

While most of the COVID-19 patients with purpuric rash are accompanied by itching, a positive Koebner phenomenon has been reported in the literature in a patient with purpuric rash $(39,40)$. In two case series including a small number of patients with purpuric rash, it was reported that purpuric lesions started after COVID-19 symptoms $(25,41)$. De Giorgi et al. reported 13 patients with petechial / purpura and signs of acro ischemia. It has been reported that these lesions are seen in more severe COVID-19 cases and purpuric / acroischemic lesions indicate increased prothrombin time, fibrinogen and D-dimer levels in patients (17). Similarly, in another study, it was reported that 4 patients out of 34 had petechial / purpuric lesions and these patients were middle-aged and severe cases. Interestingly, in two of these four patients, purpuric lesions are accompanied by atypical polymorphic papulovesicular lesions, while in another patient, urticarial lesions are concurrent with purpuric lesions (25).

In a case series of five patients with severe COVID-19 infection, purpuric skin rash was detected in three patients. Histopathological examination was performed in one of these patients with retiform purpura; leukocytoclasia and interstitial and perivascular neutrophilia were found (41). Histopathological features in petechial / purpuric lesions depend on the type of the lesion. Palpable purpura is characterized by basal layer necrosis, small vessel damage with fibrinoid necrosis, neutrophilic infiltration in the vessel walls, leukocytoclasia and erythrocyte extravasation $(40,42)$. Purpuric patches and retiform purpura is characterized by vascular ectasia, thrombus in deeply located vessels, perivascular and interstitial neutrophilic infiltration with leukocytoclasia and thrombogenic vasculopathy. In addition, diffuse necrosis of the epidermis and adnexal structures is one of the histopathological findings observed in such lesions (41). In addition, complement accumulation was found in both types of lesions $(40,41)$.

The pathogenesis of petechial / purpura lesions is thought to be pauci-inflammatory thrombogenic vasculopathy. In the immunohistochemistry study by Magro et al., it was observed that the C5b-9 and C4d components of the complement were heavily deposited in the small vessels of both lesional and perilesional skin. These complement components can sometimes be found together with COVID-19 spike glycoproteins (41). Considering the severe clinical conditions of COVID-19 patients with petechial / purpura lesions, it should be considered that the agents used for the disease can also play a role in the etiology of petechiae / purpura lesions.

\section{Livedoid Skin Lesions}

Livedo reticularis is a reddish-purplish lace-like discoloration of the skin that can be temporary or permanent. The colour change is caused by a decrease in the blood flow of the arterioles that feed the cutaneous capillaries, and the presence of deoxygenated hemoglobin gives the skin a purplish colour. While livedo reticularis that occurs due to the physiological conditions (cold exposure) or idiopathic is named primary, secondary livedo reticularis is used to describe livedoid lesions seen in the course of systematic diseases. Hematological, rheumatic, cardiovascular diseases and infections can cause secondary livedo reticularis (43).

Livedoid rashes appear to be less frequently reported during the COVID-19 pandemic compared to other types of rash. Liveoid lesions were found in $6 \%$ of the patients in a case series of 375 patients by Galvan casas et al. It is seen that the lesions are mostly located on the trunk, forearm extensor surface, and the dorsal of the hands and feet. In this case series, it is seen that livedoid lesions start simultaneously with the symptoms of COVID-19. In this study, the mean age of patients is 63 , the mean duration of the lesion is 9.4 days, and this type of skin lesions are associated with higher mortality rates compared to other lesions (12).

Velasco et al. reported a male patient with livedoid lesions coexisting with COVID-19 symptoms accompanied by acro-ischemia. In the histopathological examination, they found mild necrosis in the upper epidermis, hyaline thrombus in the papillary dermis, neutrophilic infiltration surrounding the occluded blood vessels, and fibrinoid necrosis in larger arterial structures in some regions (44). Magro et al. reported three patients with skin lesions associated with vascular involvement. In the histopathological examination of these patients, perivascular lymphocytic infiltrate and microthrombus without vasculitis were detected in deep dermis venules. They also reported that d-dimer and INR levels were increased in these patients (41). 
Although the exact mechanism of livedoid lesions is unknown, several mechanisms have been proposed. One of these theories is the relationship between COVID-19 and hypercoagulobility. In a retrospective study of 183 COVID-19 patients, it has been reported that the d-dimer and fibrin degradation products of the cases who died due to this disease were higher and the prothrombin times were longer compared to the others (45). Similarly, patients with livedoid lesions are at higher risk for hypercoagulobility, and patients with this lesion have higher mortality rates.

Manalo et al. hypothesized that livedo reticularis is caused by DIC and macrothrombosis in severe disease and by microthrombosis caused by inflammatory cytokines in milder disease (46).

\section{Thrombotic-Ischemic Lesions}

Infection-related cutaneous thrombotic and ischemic lesions might occur due to the direct vascular invasion of the infectious agent, vascular occlusion, or diffuse intravascular coagulation. These type of lesions are important symptoms of serious infections such as meningococemia, staphylococcal and pneumococcal septicemias $(47,48)$.

Chilblain lesions, also called pernio, are a localized inflammatory skin finding that causes edema and erythematous-violet discoloration in the extremities. It is triggered by exposure to cold or humid environment. While some cases are seen as idiopathic, they can also be seen in autoimmune diseases such as lupus (49). In some cases, the lesions are associated with Raynaud's phenomenon and a trigger such as cold exposure or mental stress is thought to cause skin symptoms on the extremities through vasoconstriction (50). Vasoconstriction caused by cold, vasospasm leading to hypoxemia and inflammation are various factors in the formation of these lesions. Other theories are autoantibody-induced endothelial damage and hyperviscosity (49). Considering the increasing incidence of Chilblain-like lesions and their temporal relationship with viral symptoms, the definition of "COVID toes" has come to the fore.

Chilblain-likelesionsarelesions that can causesymptoms such as itching, pain or burning, accompanied by vesicles or pustules on an erythematous and edematous background. The incidence of Chilblain-like acral lesions has increased during the COVID-19 pandemic. It has been reported in many case series that chilblainlike lesions can be found in COVID-19. The prevalence of these lesions varies between studies. In an international case series consisting of 505 patients with dermatological findings, $63 \%$ of chilblain-like lesions were reported (51). In other studies, the prevalence of chilblain-like lesions ranges from $14.3 \%$ to $72 \%(12,26,51-53)$. These types of vascular lesions have been reported mostly in adolescents and young adults, and the most common location of the lesions is the distal parts of the fingers and toes $(12,26$, $30,51,52,54-59)$. In many case series, it has been reported that the lesions start after the symptoms of COVID-19 and the lesions regress within an average of one to two weeks $(12,51,54,55)$. These types of lesions are an important clue for detecting asymptomatic cases of COVID-19.

In the case series published by Freeman et al., it was reported that in $55 \%$ of the cases, chilblain-like lesions were the only symptom of COVID-19 infection and these patients were young and had no additional disease. And in this study, the presence of chilblain-like lesions in COVID-19 was associated with mild disease (51). In the case series of Galvan Casas et al., the frequency of chilblain-like lesions was 19\%, the average age of patients with this lesion was 32.5 , and the mean duration of lesions was 12.7 days (12).

Different patterns were observed in the histopathological examination performed by Rubio-Muniz et al. They reported that in most of the Chilblain-like lesions, focal vacuolar degeneration in the basal layer, perivascular lymphocytic infiltration in the dermis and regenerative changes in the epidermis were observed. In addition, perivascular neutrophilic infiltration has been reported with epidermal necrosis in some cases (25).

The mechanism of formation of chilblain-like lesions seen in COVID-19 is not fully known. Bouaziz et al. emphasized immune dysregulation, vasculitis, vascular thrombosis and neoangiogenesis in the formation of these lesions. In this study, a large number of chilblainlike lesions were also reported in people who were in close contact with COVID-19 patients who did not have COVID-19 PCR positivity and did not show the general symptoms of COVID-19 infections. Three different hypotheses have been emphasized in the formation of these lesions. Firstly, these lesions might be caused by a confounding factor other than COVID-19. Secondly, 
they might develop due to a postviral immunological reaction in asymptomatic forms of COVID-19, and finally, they represent skin involvement of the infection in the COVID-19 patient group showing an unusual immune anti-viral response (3).

\section{PPE Induced Skin Complications}

Virus-induced or drug-related skin lesions can be seen in patients infected with SARS-CoV-2. In addition, the pandemic has indirectly caused many cutaneous complications with the use of personal protective equipment (PPE). These complications include pressure sores, contact dermatitis, urticaria, dry skin, and exacerbation of pre-existing skin diseases such as seborrheic dermatitis, atopic dermatitis, acne, and rosacea (60). Due to the possible transmission of SARSCoV-2 from asymptomatic individuals, the widespread use of PPE has become mandatory, especially to reduce infection rates among healthcare professionals and prevent viral spread. Healthcare professionals should protect themselves and their patients from disease transmission by wearing multiple types of PPE such as goggles, face shields, N95 masks, protective gowns and latex gloves. Frequent and long-term use of PPE among healthcare professionals during the COVID-19 pandemic has been associated with various skin complications (61). The fact that impaired cutaneous barriers create a potential gateway for COVID-19 infections and increase contamination is a serious concern with PPE. Masks, goggles, face shields, and gloves exert pressure on areas of contact, create skin abrasion, cause moisture and maceration, and can cause skin damage to the nose bridge, cheeks, forehead and hands. Skin damages caused by PPE include desquamation, erythema, maceration, fissure, papules, and erosions that cause itching and pain (62).

In a cross-sectional questionary study conducted by Jiang et al in China, the prevalence of skin lesions caused by the use of PPE in healthcare workers was found to be $42.8 \%$ among the 4,306 participants. In this study three types of skin injuries have been identified; pressure ulcers due to the equipment use, skin damage due to moisture, and skin tears. In the same study PPE-related skin lesions were also handled. It has been reported that the prevalence is higher among male physicians, among those who use PPE for more than 4 hours per day, among those over the age of 35 , and among the individuals who sweat a lot (61). In another study conducted with 61 healthcare workers who regularly use PPE in China, it was reported that 95.1\% of those using N95 masks developed skin lesions due to the use of masks. The most common of these lesions was pressure-related skin damage at the bridge of the nose, while the second most common skin symptom was itching on the face. Moreover, complications related to the use of latex gloves were also detected in $88.5 \%$ of the participants. These complications were dry skin, itching, redness, and skin tears. In addition, complications related to the use of protective clothing were also reported in $67 \%$ of the participants. The most common of these complications were skin dryness and itching (63).

The most notable of the complications caused by the use of PPE is pressure ulcers. While the most common location of pressure ulcers caused by personal protective equipment is the nose bridge and cheeks (59.65\%), they can also be located less frequently in the auricle, forehead, zygoma and chin. It has been reported that $98.84 \%$ of pressure ulcers reported in medical personnel are at the stage 1 and stage 2 (61).

The use of barrier films or dressings at pressure points before wearing PPE can reduce such injuries $(60,64,65)$. However, the effects of these preventive measures on the ability of PPE to prevent viral spread are not known enough, so it is crucial to be careful about this $(65,66)$.

Frequent hand washing and intensive use of hand disinfectants during the pandemic caused an increase in the incidence of hand dermatitis both in healthcare workers and in the general population. In addition, frequent washing of hands and keeping them moist in gloves for a long time increases the risk of pseudomonas colonization and infection in the nails. This situation is also important in terms of the risk of transmission to patients in the intensive care unit. The use of regular moisturizing and barrier creams, washing hands with warm water instead of hot water, and reducing the use of alcohol-based hand disinfectants as much as possible provide benefits in terms of preventing hand eczema (62). The American Academy of Dermatology has published recommendations for the prevention and treatment of occupational dermatological problems during the pandemic. Following these recommendations will be beneficial in protecting healthcare professionals from possible skin complications due to the PPE use (67). 


\section{DISCUSSION}

Among the exanthems that have been mentioned above, maculopapular lesions are the most common, and they are followed by urticarial, vesicular and MIS-C lesions. Maculopapular and urticarial exanthems are typically associated with severe COVID-19 infections and are more common in middle-aged and elderly patients. The time of onset of maculopapular and urticarial lesions varies between studies. These two types of lesions are not helpful in terms of the diagnosis of COVID-19 because these lesions can also occur as a side effect of drugs used in the treatment of infection.

Although the onset of vesicular rash varies, most of them begin after systemic symptoms. It has been reported that it starts before systemic symptoms in very few cases. The mean age of vesicular lesions is $57.44 \pm 17.26$ years for men and $58.80 \pm 15.918$ years for women and associated with intermedium severity. This rash type is thought to be the specific rash of COVID-19.

MIS-C is a new, serious disease seen in childhood with a lot of unknown clinical features. Despite the lack of information, published data suggest that most MIS-C patients develop skin symptoms.

Vascular lesions associated with COVID-19 can be categorized as chilblain-like, petechiae / purpura or livedoid. Chilblain-like lesions are very similar to pernio lesions that occur with cold exposure; however, unlike the pernio, these lesions are also seen in warmer weather conditions. Chilblain-like lesions are found on the fingers and toes of young patients and are associated with less severe COVID-19 infections. The onset of chilblain-like lesions is typically after the onset of COVID-19 systemic symptoms. The mean age for chillblain-like lesions ranges from 11-27 in reports and associated with less severe disease.

Petechiae / purpura lesions are more common in middleaged patients. These lesions have been associated with more severe COVID-19 infection. These lesions can be seen as acral localized, limited to the distal extremities or as diffuse involvement $(26,29)$. Livedoid lesions are among the rarest skin findings during the pandemic. They mostly occur in elderly patients and have been associated with severe COVID-19 infections (12).

The pathophysiological mechanisms behind the skin symptoms of COVID-19 are not well known, but many theories have been proposed regarding this issue. It is believed that maculopapular and urticarial rashes may occur due to adverse reactions related to drugs used in COVID-19 disease or cytokine storm during the course of the disease $(24,68)$.

Possible molecular mechanisms of Chilblain-like lesions include immune dysregulation, vasculitis, vascular thrombosis, and neoangiogenesis (3). In the pathogenesis of petechiae / purpuric skin lesions, it is possible to mention about a pauci-inflammatory thrombogenic vasculopathy with dense accumulation of complement components C5b-9 and C4d in the cutaneous microvascular system (41). Also, in the formation of these lesions, cutaneous side effects of the drugs used in the treatment of the disease might be involved.

Livedoid lesions are thought to be due to DIC and macrothrombosis in severe cases and microthrombosis triggered by inflammatory cytokines in milder cases. While vesicular lesions are caused by cytokine storm due to the immune system hyperactivity, there is no definite information about the pathophysiology of MIS-C lesions.

In the covid-19 pandemic, due to the use of PPE and frequent and excessive disinfectants, both primary dermatological problems can develop and exacerbation of existing skin diseases can be seen. This situation once again increases the importance of dermatologists in the pandemic.

Finally, it should be kept in mind that the cutaneous symptoms seen during the pandemic can be a direct effect of the SARS-CoV-2 virus. The possibility of COVID-19 should be carefully evaluated in patients whose skin findings are reported during the pandemic. Given the high mortality rate of the infection, timely and accurate identification of the relevant cutaneous symptoms can play a key role in early diagnosis and treatment. It is clear that more in-depth research is needed to understand the relationship between COVID-19 and the skin.

As a result, different cutaneous symptoms have been described in the COVID-19 pandemic. Although its pathogenic mechanisms are still unclear, it has been stated that hyperactive immune response, complement activation and microvascular damage play a role in the formation of skin findings. On the other hand, the 
effects of other infectious agents, patient comorbidities, immune status, concomitant treatments and other still unidentified factors are still the main controversy. Cutaneous findings that can cause suspicion of COVID-19 and identify potentially infectious cases carry dermatologists to an important position in terms of pandemics. Moreover, the role of skin findings associated with COVID-19 as prognostic markers needs to be clarified. However, the literature data show a great heterogeneity in cutaneous manifestations, in their time to occur, and in extracutaneous symptoms associated with skin manifestations. In patients with skin findings and asymptomatic in terms of SARS-CoV-2, skin findings can easily be confused with allergic diseases and other viral diseases. Therefore, clinicians should be aware of the skin involvement in COVID-19 to make an early diagnosis. On the other hand, more histological and clinical studies are required to demonstrate the mechanisms of cutaneous findings.

\section{Declarations}

The authors received no financial support for the research and/or authorship of this article. There is no conflict of interest.

\section{REFERENCES}

1. Erganiş S, Bozdayı G. Virology, immunity and vaccine development of SARS-CoV-2. Arch Curr Med Res. 2021;2(1):05-13.

2. Drago F, Ciccarese G, Gasparini G, Cogorno L, Javor S, Toniolo A, et al. Contemporary infectious exanthems: an update. Future Microbiol. 2017;12:171-93.

3. Bouaziz JD, Duong TA, Jachiet M, Velter C, Lestang P, Cassius C, et al. Vascular skin symptoms in COVID-19: a French observational study. J Eur Acad Dermatol Venereol. 2020;34(9):e451-2.

4. Almutairi N, Schwartz RA. COVID-19 with dermatologic manifestations and implications: An unfolding conundrum. Dermatol Ther. 2020;33(5):e13544.

5. Tang K, Wang Y, Zhang H, Zheng Q, Fang R, Sun Q. Cutaneous manifestations of the coronavirus disease 2019 (COVID-19): A brief review. Dermatol Ther. 2020;33(4):e13528.

6. Ghazal S, Litvinov I V, Aljahani N, Jfri A, Netchiporouk E. Cutaneous manifestations of coronavirus disease 2019 (COVID-19) infection-what do we know so far? J Cutan Med Surg. 24(4):416-7.

7. Suchonwanit P, Leerunyakul K, Kositkuljorn C. Diagnostic and prognostic values of cutaneous manifestations in COVID-19. Dermatol Ther. 2020;33(4).

8. Fu L, Wang B, Yuan T, Chen X, Ao Y, Fitzpatrick T, et al. Clinical characteristics of coronavirus disease 2019 (COVID-19) in China: A systematic review and meta-analysis. J Infect. 2020;80(6):656-65.
9. Recalcati S. Cutaneous manifestations in COVID-19: a first perspective. J Eur Acad Dermatol Venereol. 2020;34(5):e212-3.

10. Hedou M, Carsuzaa F, Chary E, Hainaut E, Cazenave-Roblot F, Masson Regnault M. Comment on "Cutaneous manifestations in COVID-19: a first perspective" by Recalcati S. J Eur Acad Dermatol Venereol. 2020;34(7):e299-300.

11. Radonjic-Hoesli S, Hofmeier KS, Micaletto S, SchmidGrendelmeier P, Bircher A, Simon D. Urticaria and angioedema: an update on classification and pathogenesis. Clin Rev Allergy Immunol. 2018;54(1):88-101.

12. Galván Casas $C$, Català $A$, Carretero Hernández G, RodríguezJiménez P, Fernández-Nieto D, Rodríguez-Villa Lario A, et al. Classification of the cutaneous manifestations of COVID-19: a rapid prospective nationwide consensus study in Spain with 375 cases. Br J Dermatol. 2020;183(1):71-7.

13. Henry D, Ackerman M, Sancelme E, Finon A, Esteve E. Urticarial eruption in COVID-19 infection. J Eur Acad Dermatol Venereol. 2020;34(6):e244-5.

14. van Damme C, Berlingin E, Saussez S, Accaputo O. Acute urticaria with pyrexia as the first manifestations of a COVID-19 infection. J Eur Acad Dermatol Venereol. 2020;34(7):e300-1.

15. Criado PR, Abdalla BMZ, de Assis IC, van Blarcum de Graaff Mello C, Caputo GC, Vieira IC. Are the cutaneous manifestations during or due to SARS-CoV-2 infection/COVID-19 frequent or not? Revision of possible pathophysiologic mechanisms. Inflamm Res. 2020;69(8):745-56.

16. Kang JH. Febrile illness with skin rashes. Infect Chemother. 2015;47(3):155-66.

17. De Giorgi V, Recalcati S, Jia Z, Chong W, Ding R, Deng Y, et al. Cutaneous manifestations related to coronavirus disease 2019 (COVID-19): A prospective study from China and Italy. J Am Acad Dermatol. 2020;83(2):674-5.

18. Sachdeva M, Gianotti R, Shah M, Bradanini L, Tosi D, Veraldi $\mathrm{S}$, et al. Cutaneous manifestations of COVID-19: Report of three cases and a review of literature. J Dermatol Sci. 2020 May;98(2):75-81.

19. Paolino G, Canti V, Mercuri SR, Rovere Querini P, Candiani M, Pasi F. Diffuse cutaneous manifestation in a new mother with COVID-19 (SARS-Cov-2). Int J Dermatol. 2020;59(7):874-5.

20. Ahouach B, Harent S, Ullmer A, Martres P, Bégon E, Blum L, et al. Cutaneous lesions in a patient with COVID-19: are they related? Br J Dermatol. 2020;183(2):e31.

21. Morey-Olivé M, Espiau M, Mercadal-Hally M, Lera-Carballo E, García-Patos V. Cutaneous manifestations in the current pandemic of coronavirus infection disease (COVID 2019). An Pediatr. 2020;92(6):374-5

22. Avellana Moreno R, Estela Villa LM, Avellana Moreno V, Estela Villa C, Moreno Aparicio MA, Avellana Fontanella JA. Cutaneous manifestation of COVID-19 in images: a case report. J Eur Acad Dermatology Venereol. 2020;34(7).

23. Putra BE, Adiarto S, Dewayanti SR, Juzar DA. Viral exanthem with "Spins and needles sensation" on extremities of a COVID-19 patient: A self-reported case from an Indonesian medical frontliner. Int J Infect Dis. 2020;96:355-8.

24. Herrero-Moyano M, Capusan TM, Andreu-Barasoain M, Alcántara-González J, Ruano-Del Salado M, Sánchez-Largo Uceda ME, et al. A clinicopathological study of eight patients with COVID-19 pneumonia and a late-onset exanthema. J Eur Acad Dermatol Venereol. 2020;34(9):e460-4. 
25. Rubio-Muniz CA, Puerta-Peña M, Falkenhain-López D, ArroyoAndrés J, Agud-Dios M, Rodriguez-Peralto JL, et al. The broad spectrum of dermatological manifestations in COVID-19: clinical and histopathological features learned from a series of 34 cases. J Eur Acad Dermatol Venereol. 2020;34(10):e574-6.

26. De Masson A, Bouaziz J-D, Sulimovic L, Cassius C, Jachiet M, Ionescu M-A, et al. Chilblains is a common cutaneous finding during the COVID-19 pandemic: A retrospective nationwide study from France. J Am Acad Dermatol. 2020;83(2):667-70.

27. Bursal Duramaz B, Yozgat CY, Yozgat Y, Turel O. Appearance of skin rash in pediatric patients with COVID-19: Three case presentations. Dermatol Ther. 2020;33(4):e13594.

28. Marzano A V., Cassano N, Genovese G, Moltrasio C, Vena GA. Cutaneous manifestations in patients with COVID-19: a preliminary review of an emerging issue. Br J Dermatol. 2020;183(3):431-42.

29. Askin O, Altunkalem RN, Altinisik DD, Uzuncakmak TK, Tursen U, Kutlubay Z. Cutaneous manifestations in hospitalized patients diagnosed as COVID-19. Dermatol Ther. 2020;33(6):e13896.

30. Fernandez-Nieto D, Ortega-Quijano D, Jimenez-Cauhe J, BurgosBlasco P, de Perosanz-Lobo D, Suarez-Valle A, et al. Clinical and histological characterization of vesicular COVID-19 rashes: a prospective study in a tertiary care hospital. Clin Exp Dermatol. 2020;45(7):872-5.

31. Marzano AV, Genovese G, Fabbrocini G, Pigatto P, Monfrecola G, Piraccini BM, et al. Varicella-like exanthem as a specific COVID19-associated skin manifestation: Multicenter case series of 22 patients. J Am Acad Dermatol. 2020;83(1):280-5.

32. Galeotti C, Bayry J. Autoimmune and inflammatory diseases following COVID-19. Nat Rev Rheumatol. 2020;16(8):413-4.

33. Verdoni L, Mazza A, Gervasoni A, Martelli L, Ruggeri M, Ciuffreda M, et al. An outbreak of severe Kawasaki-like disease at the Italian epicentre of the SARS-CoV-2 epidemic: an observational cohort study. Lancet. 2020;395(10239):1771-8.

34. Ebina-Shibuya R, Namkoong H, Shibuya Y, Horita N. Multisystem inflammatory syndrome in children (MIS-C) with COVID-19: Insights from simultaneous familial Kawasaki Disease cases. Int J Infect Dis. 2020;97:371-3.

35. Whittaker E, Bamford A, Kenny J, Kaforou M, Jones CE, Shah $\mathrm{P}$, et al. Clinical characteristics of 58 children with a pediatric inflammatory multisystem syndrome temporally associated with SARS-CoV-2. JAMA. 2020;324(3):259-69.

36. Miller J, Cantor A, Zachariah P, Ahn D, Martinez M, Margolis KG Gastrointestinal symptoms as a major presentation component of a novel multisystem inflammatory syndrome in children that is related to coronavirus disease 2019: A single center experience of 44 cases. Gastroenterology. 2020;159(4):1571-1574.e2.

37. Hameed S, Elbaaly H, Reid CEL, Santos RMF, Shivamurthy V, Wong J, et al. Spectrum of imaging findings at chest radiography, US, CT, and MRI in multisystem inflammatory syndrome in children associated with COVID-19. Radiology. 2021;298(1):E1-10.

38. McCrindle BW, Manlhiot C. SARS-CoV-2-Related inflammatory multisystem syndrome in children: Different or shared etiology and pathophysiology as kawasaki disease? JAMA. 2020;324(3):246-8.

39. Castelnovo L, Capelli F, Tamburello A, Faggioli PM, Mazzone A. Symmetric cutaneous vasculitis in COVID-19 pneumonia. J Eur Acad Dermatol Venereol. 2020;34(8):e362-3.
40. Dominguez-Santas M, Diaz-Guimaraens B, Garcia Abellas P, MorenoGarcia Del Real C, Burgos-Blasco P, Suarez-Valle A. Cutaneous smallvessel vasculitis associated with novel 2019 coronavirus SARS-CoV-2 infection (COVID-19). J Eur Acad Dermatol Venereol. 2020;34(10):e5367.

41. Magro C, Mulvey JJ, Berlin D, Nuovo G, Salvatore S, Harp J, et al Complement associated microvascular injury and thrombosis in the pathogenesis of severe COVID-19 infection: A report of five cases. Transl Res. 2020;220:1-13.

42. Mayor-Ibarguren A, Feito-Rodriguez M, Quintana Castanedo L, RuizBravo E, Montero Vega D, Herranz-Pinto P. Cutaneous small vessel vasculitis secondary to COVID-19 infection: a case report. J Eur Acad Dermatol Venereol. 2020;34(10):e541-2.

43. Sajjan VV, Lunge S, Swamy MB, Pandit AM. Livedo reticularis: A review of the literature. Indian Dermatol Online J. 6(5):315-21.

44. Llamas-Velasco M, Muñoz-Hernández P, Lázaro-González J, ReolidPérez A, Abad-Santamaría B, Fraga J, et al. Thrombotic occlusive vasculopathy in a skin biopsy from a livedoid lesion of a patient with COVID-19. Br J Dermatol. 2020;183(3):591-3.

45. Tang N, Li D, Wang X, Sun Z. Abnormal coagulation parameters are associated with poor prognosis in patients with novel coronavirus pneumonia. J Thromb Haemost. 2020;18(4):844-7.

46. Manalo IF, Smith MK, Cheeley J, Jacobs R. A dermatologic manifestation of COVID-19: Transient livedo reticularis. J Am Acad Dermatol. 2020;83(2):700.

47. Launay E, Gras-Le Guen C, Martinot A, Assathiany R, Blanchais $\mathrm{T}$, Mourdi N, et al. Suboptimal care in the initial management of children who died from severe bacterial infection: a population-based confidential inquiry. Pediatr Crit Care Med. 2010;11(4):469-74.

48. Thompson MJ, Ninis N, Perera R, Mayon-White R, Phillips C, Bailey $\mathrm{L}$, et al. Clinical recognition of meningococcal disease in children and adolescents. Lancet. 2006;367(9508):397-403.

49. Cappel JA, Wetter DA. Clinical characteristics, etiologic associations, laboratory findings, treatment, and proposal of diagnostic criteria of pernio (chilblains) in a series of 104 patients at Mayo Clinic, 2000 to 2011. Mayo Clin Proc. 2014;89(2):207-15.

50. Hughes M, Herrick AL. Raynaud's phenomenon. Best Pract Res Clin Rheumatol. 2016;30(1):112-32.

51. Freeman EE, McMahon DE, Lipoff JB, Rosenbach M, Kovarik C, Takeshita J, et al. Pernio-like skin lesions associated with COVID-19: A case series of 318 patients from 8 countries. J Am Acad Dermatol. 2020;83(2):486-92.

52. Docampo-Simón A, Sánchez-Pujol MJ, Juan-Carpena G, PalazónCabanes JC, Vergara-De Caso E, Berbegal L, et al. Are chilblain-like acral skin lesions really indicative of COVID-19? A prospective study and literature review. J Eur Acad Dermatol Venereol. 2020;34(9):e445-7.

53. Duong TA, Velter C, Rybojad M, Comte C, Bagot M, Sulimovic L, et al. Did Whatsapp ${ }^{\circledR}$ reveal a new cutaneous COVID-19 manifestation? J Eur Acad Dermatol Venereol. 2020;34(8):e348-50.

54. Colonna C, Genovese G, Monzani NA, Picca M, Boggio F, Gianotti $\mathrm{R}$, et al. Outbreak of chilblain-like acral lesions in children in the metropolitan area of Milan, Italy, during the COVID-19 pandemic. J Am Acad Dermatol. 2020;83(3):965-9.

55. Andina D, Noguera-Morel L, Bascuas-Arribas M, Gaitero-Tristán J, Alonso-Cadenas JA, Escalada-Pellitero S, et al. Chilblains in children in the setting of COVID-19 pandemic. Pediatr Dermatol. 2020;37(3):40611.

56. Wollina U, Karadağ AS, Rowland-Payne C, Chiriac A, Lotti T. Cutaneous signs in COVID-19 patients: A review. Dermatol Ther. 2020;33(5):e13549. 
57. Gaspari V, Neri I, Misciali C, Patrizi A. COVID-19: how it can look on the skin. Clinical and pathological features in 20 COVID-19 patients observed in Bologna, north-eastern Italy. J Eur Acad Dermatol Venereol. 2020;34(10):e552-3.

58. Garcia-Lara G, Linares-González L, Ródenas-Herranz T, RuizVillaverde R. Chilblain-like lesions in pediatrics dermatological outpatients during the COVID-19 outbreak. Dermatol Ther. 2020;33(5):e13516.

59. El Hachem M, Diociaiuti A, Concato C, Carsetti R, Carnevale C, Ciofi Degli Atti M, et al. A clinical, histopathological and laboratory study of 19 consecutive Italian paediatric patients with chilblainlike lesions: lights and shadows on the relationship with COVID-19 infection. J Eur Acad Dermatol Venereol. 2020;34(11):2620-9.

60. Yan Y, Chen H, Chen L, Cheng B, Diao P, Dong L, et al. Consensus of Chinese experts on protection of skin and mucous membrane barrier for health-care workers fighting against coronavirus disease 2019. Dermatol Ther. 2020;33(4):e13310.

61. Jiang Q, Song S, Zhou J, Liu Y, Chen A, Bai Y, et al. The prevalence, characteristics and prevention status of skin injury caused by personal protective equipment among medical staff in fighting COVID-19: A multicenter, cross-sectional study. Adv wound care. 2020;9(7):357-64.

62. Lan J, Song Z, Miao X, Li H, Li Y, Dong L, et al. Skin damage among health care workers managing coronavirus disease-2019. J Am Acad Dermatol. 2020;82(5):1215-6.

63. Hu K, Fan J, Li X, Gou X, Li X, Zhou X. The adverse skin reactions of health care workers using personal protective equipment for COVID-19. Medicine (Baltimore). 2020;99(24):e20603.

64. Elston DM. Occupational skin disease among health care workers during the coronavirus (COVID-19) epidemic. J Am Acad Dermatol. 2020;82(5):1085-6.

65. Oranges T, Janowska A, Dini V. Reply to: "Skin damage among health care workers managing coronavirus disease-2019". J Am Acad Dermatol. 2020;82(6):e233-4.

66. Kantor J. Behavioral considerations and impact on personal protective equipment use: Early lessons from the coronavirus (COVID-19) pandemic. J Am Acad Dermatol. 2020;82(5):1087-8.

67. American Academy of Dermatology. Preventing and treating occupationally induced dermatologic conditions during COVID-19. Available at: https: / www. aad.org/public/diseases/coronavirus / occ-induced/ Accessed March 21,2021.

68. Türsen Ü, Türsen B, Lotti T. Cutaneous side-effects of the potential COVID-19 drugs. Dermatol Ther. 2020;33(4):e13476. 